\begin{tabular}{|c|c|c|}
\hline ISSN (Online): 2367-6957 & $67-6957$ & ISSN (Print): 2367-6361 \\
\hline & Izvestiya Journal of Varna University of Economics 1 (2021) & VESTIYA \\
\hline & IZVESTIY A & $=$ \\
\hline D. & $\begin{array}{c}\text { Journal of Varna University of Economics } \\
\text { http://journal.ue-varna.bg }\end{array}$ & 6 \\
\hline
\end{tabular}

\title{
ECONOMIC GROWTH AND HUMAN NETWORKING
}

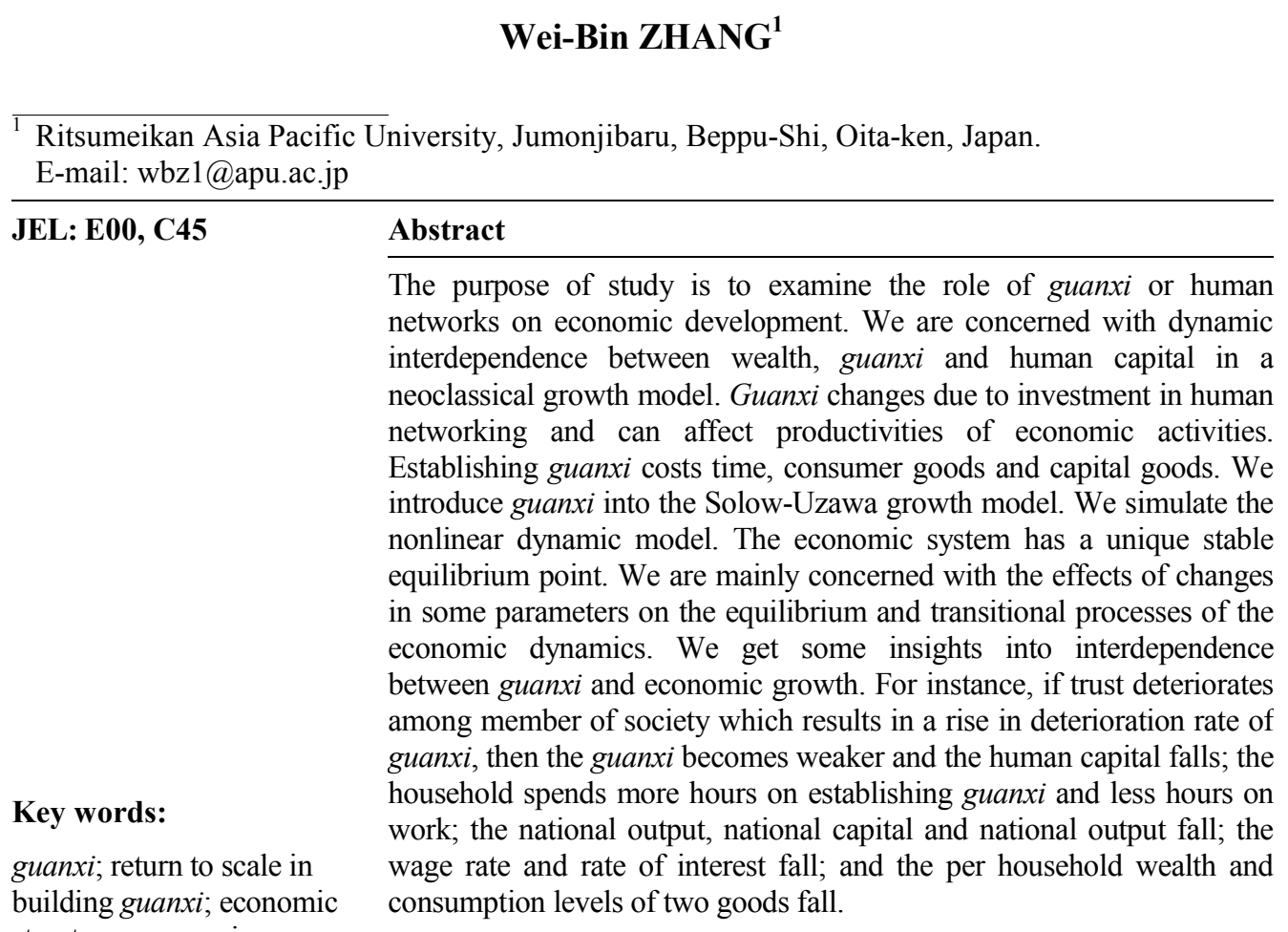
structure; economic growth.

(C) 2021 University of Economics - Varna

Citation: ZHANG, Wei-Bin (2021). Economic Growth and Human Networking. Izvestiya Journal of Varna University of Economics, 65 (1), pp. 5 - 25. DOI: 10.36997/IJUEV2021.65.1.5

\section{Introduction}

The purpose of this study is to incorporate endogenous guanxi in neoclassical growth theory. In the 1980s guanxi had already appeared in the literature of business that 
emphasizes cultural factors in doing business in China (Butterfield, 1983; Alston, 1989; Ai, 2006; Lee and Anderson, 2007). Fan (2002: 544) observes: "It was believed that right guanxi was a vital factor in business negotiation, and could bring a wide range of benefits: securing rare resources, bypassing or short-cutting the bureaucratic maze, obtaining information and privilege, selling otherwise unsellable goods, providing insurance against uncertainty and assistance when problems arose." This study is related to "capital" aspects of guanxi in the sense that guanxi is treated as a stock variable. According to Fan (2002: 549), guanxi is a form of "social capital, an important resource that a person can tap into when there is a need to find help or support. To develop and maintain a guanxi relationship is like putting one's money into a saving account or purchasing an insurance policy so that one could get help whenever he needs. Guanxi equity is a set of assets and liabilities linked to a guanxi relationship." Changes in guanxi are subject to investment and deterioration. The importance of guanxi is well-recognized in studies of Chinese management as marked by (Luo, 1997: 43) "It is widely recognized that Guanxi is a key business determinant of firm performance because the life blood of the macro and the micro business in the society is conducted through Guanxi networks." In Chinese societies, Guanxi "is essence a network of resource coalition-based stakeholders sharing resources for survival" (Su, et al. 2007: 301). "A typical Chinese company is accustomed to living in a clan-like network, called Guanxi wang (Guanxinet), which includes the direct and indirect blood relationships, distant relatives, direct and indirect friends, colleagues, schoolmates, and others with interests" (Badi, et al. 2017: 206). For individuals, organizations and firms guanxi is significant for securing favors with established long-term personal and organizational relationships (e.g., Wong and Chan, 1999; Yau et al. 2000; Yang and Wang, 2011; Shaalan, et al. 2013; Wong and Huang, 2015; Badi et al. 2017). The sustainability of guanxi is partly due to low-trust social environment, institutional uncertainties, and not properly functioning legal systems in Chinese societies (e.g., Styles and Ambler, 2003; Luo, 1997, 2008). Some studies (Yeung and Tung, 1996; Ambramson and Ai, 1999) identify guanxi as an important key determinant in doing business in China.

In a braod sense guanxi may be considered a kind of social capital. As Knack and Keefer (1997) point out, the concept of social capital implies different meanings such as trust, cooperative, and associations within groups. Putnam et al. (1993: 167) considers social capital as "those features of social organization, such as trust, norms, and networks that can improve the efficiency of society by facilitating co-ordinated actions." The way that this study models guanxi is influenced by modeling social capital in the literature of social capital and economic growth. There are many studies on relationships between social capital and economic growth (e.g., Putnam et al. 1993; Knack and Keefer, 1997; 
Wei-Bin Zhang.

Economic Growth and Human Networking

Buegelsdijk and van Schail, 2005; Iyer, et al. 2005; Bofota et al., 2016). As far as how to model social capital is modeled, this study is influenced by Bofota et al. (2016). Different from Bofota et al. (2016) who include social capital in growth model by assuming that social capital affects human capital accumulation, this study assumes that guanxi directly affects human capital. The economic mechanism of growth is based on neoclassical growth theory (Solow, 1956; Swan, 1956; Burmeister and Dobell, 1970; Zhang, 2005). This paper is structurally founded on Uzawa's two-sector growth model (Uzawa, 1961). Although this paper is built on the basis of the Uzawa framework, we introduce an alternative approach to consumer decision by Zhang (2005) to examine behavior of households. We introduce guanxi to traditional neoclassical growth theory. The rest of the paper is organized as follows. Section 2 defines the basic growth model of economic structure with incorporation of guanxi. Section 3 shows how we can follow the movement of the economic system. Section 4 examines effects of changes in some parameters on economic structural change, guanxi dynamics, and wealth accumulation over time. Section 5 concludes the study. The main results in Section 3 are shown in the Appendix.

\section{The growth model with social capital}

Our model is influenced by the Solow (1956) one-sector growth model, the Uzawa two-sector growth model, some studies on social capital and guanxi, and the approach to household decision by Zhang (1993). Our economy is composed of capital goods and consumer goods sectors. The two sectors are characterized with neoclassical production functions. All markets are perfectly competitive. Capital and labor are freely mobile between sectors. We extend the traditional two-sector growth model by incorporating guanxi. Human capital is a function of guanxi. Guanxi is built through investment which costs time, consumer goods, and capital goods. The price of capital goods is chosen to be unity. We introduce the following variables:

$\bar{N}$ - fixed population;

subscripts $i$ and $s-$ subscripts for the consumer goods sector and capital goods sector; $N_{j}(t)$ and $K_{j}(t)$ - labor force and capital input employed by sector $j$ at time $t$; $F_{j}(t)$ - the product level of sector $j$;

$T(t), \bar{T}(t)$, and $\widehat{T}(t)$ - the representative household's time spent on work, leisure, and building guanxi, respectively;

$p(t)$ - price of consumer goods;

$w(t)$ and $r(t)$ - wage rate and rate of interest;

$\Lambda(t)$ - the representative household's guanxi; 
$\bar{k}(t)$ - wealth owned by the representative household;

$c_{i}(t)$ and $c_{S}(t)$ - consumption levels of capital goods and consumption of consumer goods; and

$\delta_{k}$ and $\delta_{\Lambda}-$ fixed depreciation rate of physical capital and deterioration rate of guanxi, respectively.

\section{Total labor supply}

The total labor supply is given by

$$
N(t)=h(\Lambda(t)) T(t) \bar{N},(1)
$$

where $h(\Lambda(t))$ is level of human capital which is related to guanxi. We will explain this relation when specifying the function.

\section{Capital goods sector}

We take the production function of the capital goods sector on the following form

$$
F_{i}(t)=A_{i} K_{i}^{\alpha_{i}}(t) N_{i}^{\beta_{i}}(t), A_{i}, \alpha_{i}, \beta_{i}>0, \alpha_{i}+\beta_{i}=1,(2)
$$

where $A_{i}, \alpha_{i}$, and $\beta_{i}$ are parameters. The marginal conditions for the capital goods sector are

where $r_{\delta}(t) \equiv r(t)+\delta_{k}$.

$$
r_{\delta}(t)=\frac{\alpha_{i} F_{i}(t)}{K_{i}(t)}, w(t)=\frac{\beta_{i} F_{i}(t)}{N_{i}(t)},(3)
$$

\section{Consumer goods sector}

The production function of the consumer goods sector is taken on the following form

$$
F_{s}(t)=A_{s} K_{s}^{\alpha_{s}}(t) N_{s}^{\beta_{s}}(t), \alpha_{s}, \beta_{s}>0, \alpha_{s}+\beta_{s}=1,(4)
$$

where $A_{s}, \alpha_{s}$ and $\beta_{s}$ are parameters. The marginal conditions are

$$
r_{\delta}(t)=\frac{\alpha_{s} p(t) F_{S}(t)}{K_{S}(t)}, w(t)=\frac{\beta_{S} p(t) F_{S}(t)}{N_{S}(t)}
$$

\section{Disposable income}

We apply the approach developed by Zhang $(1993 ; 2005)$ in describing consumers' behavior. The current income is 
Wei-Bin Zhang.

Economic Growth and Human Networking

$$
y(t)=r(t) \bar{k}(t)+h(\Lambda(t)) w(t) T(t),(6)
$$

where $r(t) \bar{k}(t)$ is the interest payment and $h(\Lambda(t)) T(t) w(t)$ is the wage payment. The disposable income $\hat{y}(t)$ is the current income and the value of wealth

$$
\hat{y}(t)=y(t)+\bar{k}(t) \cdot(7)
$$

\section{Time distribution and budget}

Denote the available time for work, building guanxi, and leisure by $T_{0}$. The time distribution is given by

$$
T(t)+\bar{T}(t)+\widehat{T}(t)=T_{0} .
$$

The household uses the disposable income to consume goods, to build guanxi, and to save. We use $\omega_{s}(\Lambda(t))$ and $\omega_{i}(\Lambda(t))$ to stand for cost per unit of time in terms of consumer goods and capital goods in building guanxi. We will specify function forms of $\omega_{s}(\Lambda(t))$ and $\omega_{i}(\Lambda(t))$ when simulating the model. It should be noted that within Chinese guanxi network mianzi (face) and renqing play significant role (Hwang, 1987). Chinese face can be roughly considered as social status measured by power, wealth, and social reputation. Renqing reflects an even more complicated emotional and economic calculation. It is often referred to the exchange value in terms of public official positions, special favors, accessible to resources, that one often provides to another in the name of gift. In order to use and join in guanxi in the long term, this is a social norm that one should follow, especially for joining a long-term, extensive and complicated human network. Chinese proverb says: "Receiving a drop of beneficence should pay back a fountain of beneficence", and "One day as a teacher should be treated as the father in one's life." If one does not pay properly back when using resources within guanxi, one should lose mianzi. According to Wong (2008: 27), "Guanxi is generally a hierarchically structured network of relationship embedded with mutual obligations through a self-conscious manipulation of mianzi (face), renqing (favour) and related symbols." Due to the reciprocity, we should interpret $\omega_{s}(\Lambda(t))$ and $\omega_{i}(\Lambda(t))$ as net (assumed positive in this study) costs as one gives and receives gifts (Watt, 1999). The household is faced with the following budget constraint:

$$
p(t) c_{s}(t)+c_{i}(t)+\omega_{i}(\Lambda(t)) \hat{T}(t)+p(t) \omega_{s}(\Lambda(t)) \hat{T}(t)+s(t)=\hat{y}(t) .(9)
$$

Equation (9) shows that the expenditures on the consumption, building guanxi, and saving equals the consumers' disposable income. Substitute (8) into (9) 


$$
p(t) c_{s}(t)+c_{i}(t)+h(\Lambda(t)) w(t) \bar{T}(t)+\bar{\omega}(t) \hat{T}(t)+s(t)=\bar{y}(t),(10)
$$

where

$$
\begin{gathered}
\bar{y}(t) \equiv(1+r(t)) \bar{k}(t)+h(\Lambda(t)) T_{0} w(t), \bar{\omega}(t) \\
\equiv p(t) \omega_{s}(\Lambda(t))+\omega_{i}(\Lambda(t))+h(\Lambda(t)) w(t)
\end{gathered}
$$

We interpret $\bar{y}(t)$ as the maximum disposable income for given wealth and human capital and $\bar{\omega}(t)$ as the opportunity cost for building guanxi.

\section{Utility function and optimal decision}

Utility level $U(t)$ of the representative household is related to $c_{S}(t), c_{i}(t), \bar{T}(t)$, $\widehat{T}(t)$ and $s(t)$ as follows:

$$
U(t)=c_{s}^{\gamma_{0}}(t) c_{i}^{\xi_{0}}(t) \bar{T}^{\sigma_{0}}(t) \widehat{T}^{\theta_{0}}(t) s^{\lambda_{0}}(t), \sigma_{0}, \theta_{0}, \gamma_{0}, \xi_{0}, \lambda_{0}>0,
$$

where $\gamma_{0}, \xi_{0}, \sigma_{0}, \theta_{0}$, and $\lambda_{0}$ are defined as propensities to consume good, to consume capital goods, to use leisure time, to use time for building guanxi, and to hold wealth, respectively. Maximize $U(t)$ subject to (10)

$$
\begin{gathered}
c_{s}(t)=\frac{\gamma \bar{y}(t)}{p(t)}, c_{i}(t)=\xi \bar{y}(t), \bar{T}(t)=\frac{\sigma \bar{y}(t)}{h(\Lambda(t)) w(t)}, \hat{T}(t)=\frac{\theta \bar{y}(t)}{\bar{\omega}(t)}, s(t) \\
=\lambda \bar{y}(t),(11)
\end{gathered}
$$

where

$$
\gamma \equiv \rho \gamma_{0}, \xi \equiv \rho \xi_{0}, \sigma \equiv \rho \sigma_{0}, \theta \equiv \rho \theta_{0}, \lambda \equiv \rho \lambda_{0}, \rho \equiv \frac{1}{\gamma_{0}+\xi_{0}+\sigma_{0}+\theta_{0}+\lambda_{0}} .
$$

\section{Wealth accumulation}

Saving minus dissaving equals the wealth change. In our approach $s(t)$ is saving and $\bar{k}(t)$ is dissaving. The following equation describes the change in wealth:

$$
\dot{\bar{k}}(t)=s(t)-\bar{k}(t) .(12)
$$

\section{Full employment of capital and labor}

Full employment of the total capital stock $K(t)$ and labor force implies

$$
K_{i}(t)+K_{s}(t)=K(t), N_{i}(t)+N_{s}(t)=N(t) .
$$

\section{Demand of and supply for two goods}

We have the following equilibrium condition for consumer goods 


$$
c_{S}(t) \bar{N}+\omega_{s}(\Lambda(t)) \hat{T}(t) \bar{N}=F_{S}(t) .(14)
$$

The equilibrium condition for capital goods as follows

$$
c_{i}(t) \bar{N}+\omega_{i}(\Lambda(t)) \bar{N}+s(t) \bar{N}+\delta_{k} K(t)=F_{i}(t)+\bar{k}(t) \bar{N} . \text { (15) }
$$

\section{Wealth owned by the households and national output}

All wealth is owned by households

$$
\bar{k}(t) \bar{N}=K(t) \cdot(16)
$$

We define output per household $f(t)$ and national output $Y(t)$ as

$$
Y(t)=F_{i}(t)+p(t) F_{s}(t), f(t) \equiv \frac{Y(t)}{\bar{N}}
$$

\section{Dynamics of social capital}

We propose the following equation for building guanxi

$$
\dot{\Lambda}(t)=\frac{u \widehat{T}(t)}{\Lambda^{\chi}(t)}-\delta_{\Lambda} \Lambda(t),
$$

where $u, \chi$, and $a$ are parameters. We require $u$ and $a$ non-negative. The term $u_{s} \widehat{T}^{a_{s}} /$ $\Lambda^{\chi_{s}}$ implies that a rise in time spent on building guanxi augments guanxi. Guanxi accumulation is characterized of decreasing (increasing) of return to scales if $\chi>(<) 0$.

We built the dynamic growth model with endogenous guanxi.

\section{The Dynamics of the Economy}

The appendix shows that the movement of the national economy can be described by two differential equations with $z(t)$ and $\Lambda(t)$ as the variables, where $z(t) \equiv$ $w(t) /\left(r(t)+\delta_{k}\right)$. The following lemma shows how we follow the movement of all the variables of the dynamic system.

\section{Lemma}

We can determine the movement of $\bar{k}(t)$ and $\Lambda(t)$ is by the following two differential equations

$$
\begin{gathered}
\dot{\Lambda}(t)=\Omega_{\Lambda}(z(t), \Lambda(t)), \\
\dot{z}(t)=\Omega_{z}(z(t), \Lambda(t)),(19)
\end{gathered}
$$

where $\Omega_{\Lambda}$ and $\Omega_{z}$ are functions of $\Lambda(t)$ and $z(t)$ defined in the Appendix. We have all 
the other variables as functions of $\Lambda(t)$ and $z(t)$ as follows: $r(t)$ and $w(t)$ by (A2) $\rightarrow$ $p(t)$ by (A3) $\rightarrow \bar{k}(t)$ by (A13) $\rightarrow \bar{y}(t)$ by (A4) $\rightarrow K(t)$ by (16) $\rightarrow N_{s}(t)$ by (A6) $\rightarrow$ $T(t)$ by (A7) $\rightarrow N(t)$ by (A8) $\rightarrow N_{i}(t)$ by (A9) $\rightarrow K_{i}(t)$ and $K_{s}(t)$ by (A1) $\rightarrow F_{i}(t)$ by $(2) \rightarrow F_{S}(t)$ by $(4) \rightarrow c_{S}(t), c_{i}(t), \bar{T}(t)$ and $\widehat{T}(t)$ by (11).

Equations (19) determine the movement of the two state variables, $\Lambda(t)$ and $z(t)$. From the procedure in the Lemma we get the values of all the variables at any point of time. We simulate the model by specifying parameter values as follows:

$$
\begin{aligned}
& N=100, T_{0}=24, A_{i}=1, A_{s}=0.8, \alpha_{i}=0.3, \alpha_{s}=0.33, \lambda_{0}=0.7, \xi_{0}=0.08 \text {, } \\
& \gamma_{0}=0.1, \theta_{0}=0.02, \sigma_{0}=0.2, \chi_{s}=0.4, u=0.5, a=0.4, \delta_{k}=0.05, \delta_{\Lambda} \\
& =0.05 \text {. }(20)
\end{aligned}
$$

We measure the size of the population 100 . The propensity to consume consumer goods and to consume capital goods are respectively 0.06 and 0.08 . The propensity to save is 0.7 . The propensity to build guanxi is 0.02 . We will change this value to see how a higher propensity for building guanxi affects macroeconomic and microeconomic variables. The depreciation rate of physical capital is fixed 5 percent. The deterioration rate of physical capital is fixed 5 percent. The guanxi building exhibits decreasing return to scale in investment. We specify the human capital function as follows:

$$
h(t)=0.8 e^{0.2 \Lambda(t)-0.1 \Lambda^{1.2}(t)} .
$$

The relationships between human capital and guanxi is plotted in Figure 1. For low level of guanxi human capital rises in association with increases in guanxi; for high level of guanxi human capital falls as guanxi becomes more complicated. High complexity of guanxi does not enhance human capital as more complicated guanxi may make some firms employ people who are not qualified for jobs, which imply that effective human capital is reduced in the society. 
Wei-Bin Zhang.

Economic Growth and Human Networking

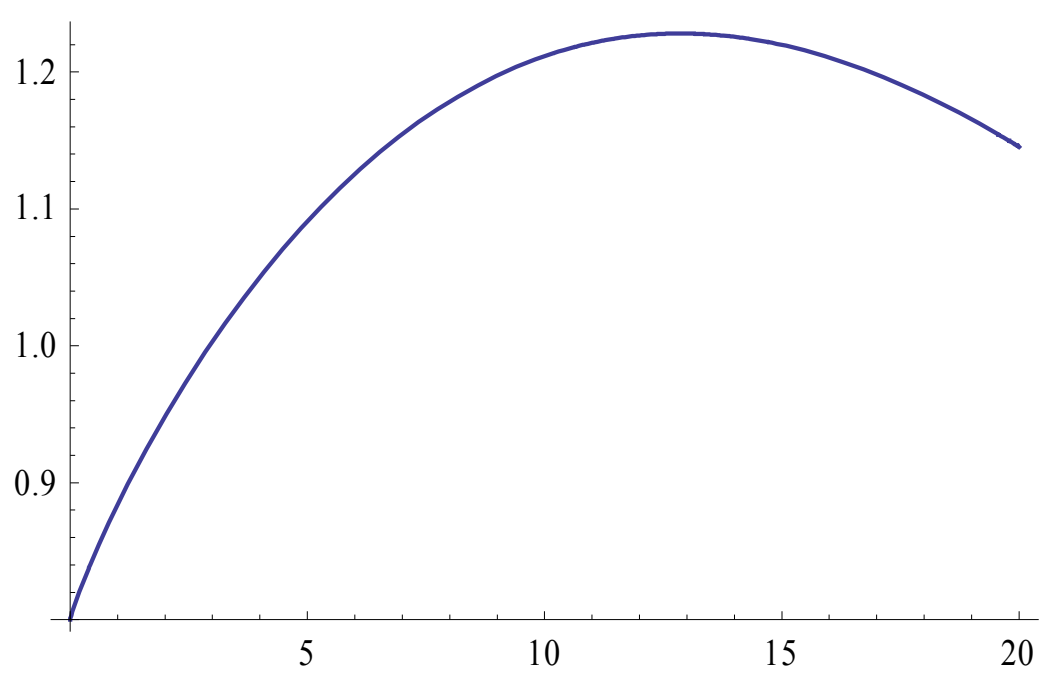

Figure 1. Relationship between Human Capital and Guanxi

We specify the cost functions as follows $\omega_{i}(\Lambda(t))=0.4 \Lambda^{0.6}(t), \omega_{s}(\Lambda(t))=0.5 \Lambda^{0.6}(t)$.

It implies that costs rise with decreasing returns to scale as human networks become more complicated. We choose the initial conditions:

$$
z(0)=0.07, \Lambda(0)=3.5 \text {. }
$$

The movement of the national economy described in Figure 2. The guanxi and human capital rise. The national output and national labor force rise. The national wealth falls. The wage rate falls and rate of interest rises. The consumer goods sector shrinks and capital goods sector expands. The household spends fewer hours on guanxi building in tandem with rises in costs building in terms of consumer goods and capital goods. The household spends more time on work and less time on leisure. The household's consumption levels of two goods and wealth fall. 

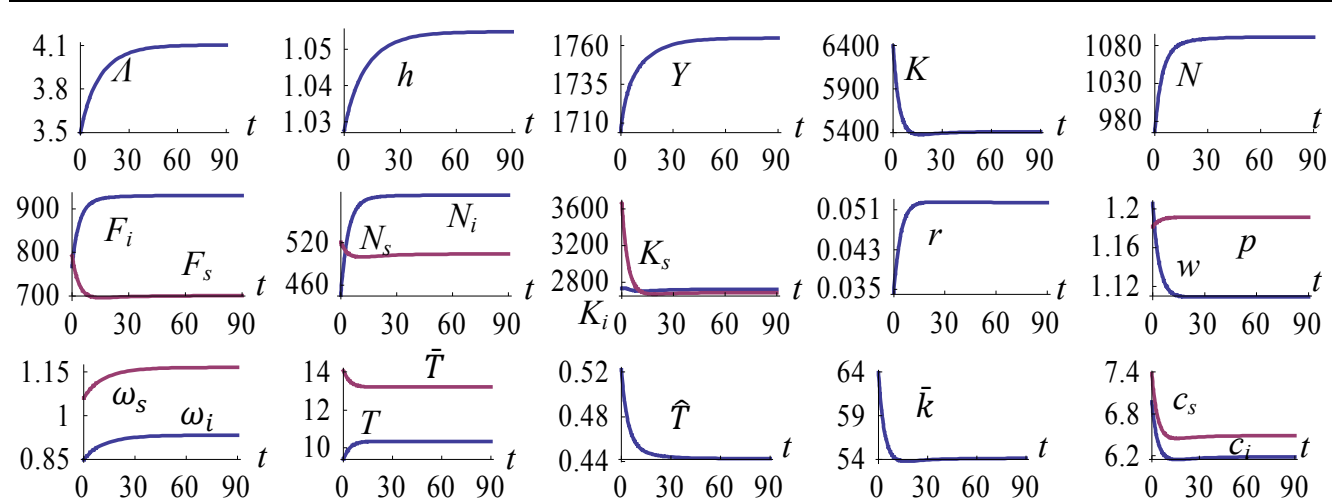

Figure 2. The Motion of the National Economy

We calculate the equilibrium values of the variables as follows

$$
\begin{aligned}
& \Lambda=4.1, Y=1765, N=1091.1, K=5411, F_{i}=930.3, F_{s}=700.5, K_{i}=2723.5, \\
& K_{s}=2685, N_{i}=587, N_{s}=504, h=1.06, r=0.05, w=1.11, p=1.19, \omega_{i}= \\
& 0.93, \\
& \omega_{s}=1.17, \bar{k}=54.1, c_{i}=6.18, c_{s}=6.49, T=10.3, \bar{T}=13.2, \widehat{T}=0.44 .
\end{aligned}
$$

the two eigenvalues are respectively -0.259 and -0.075 . The equilibrium point is stable. This result is important as it guarantees that we can effectively conduct comparative dynamic analysis.

\section{Comparative Dynamic Analysis}

We plotted the motion of all the variables in Figure 2. This also means that we can easily plot how the movement of the system is affected if the system is subject to any exogenous change. This section conducts comparative dynamic analysis with regards to some exogenous changes. We introduce a variable $\bar{\Delta} x(t)$ to represent for the change rate of the variable $x(t)$ in percentage due to changes in the parameter value.

\subsection{Lower trust in society}

Trust is considered an important factor for economic growth. It is closely related to guanxi (Leung, et al. 2005). The deterioration rate of guanxi is enhanced, for instance, people more easily lose mutual trust. We deal with the impact of the following fall in the deterioration rate of guanxi $\delta_{\Lambda}: 0.05 \Rightarrow 0.055$. We plot the simulation result in Figure 3 . Guanxi becomes weakened. The human capital falls. The household spends more hours on accumulating guanxi and fewer hours on work. Leisure time is slightly affected. The national output, national capital and national output fall. The wage rate and rate of 
Wei-Bin Zhang.

Economic Growth and Human Networking

interest fall. The price of consumer goods slightly changes. The capital goods sector shrinks initially and expands in the long term. The two sectors shrink. Per household wealth and consumption levels of two goods fall. We conclude that lower trust among the population worsen macroeconomic and microeconomic variables. The national economy is harmed by low trust.
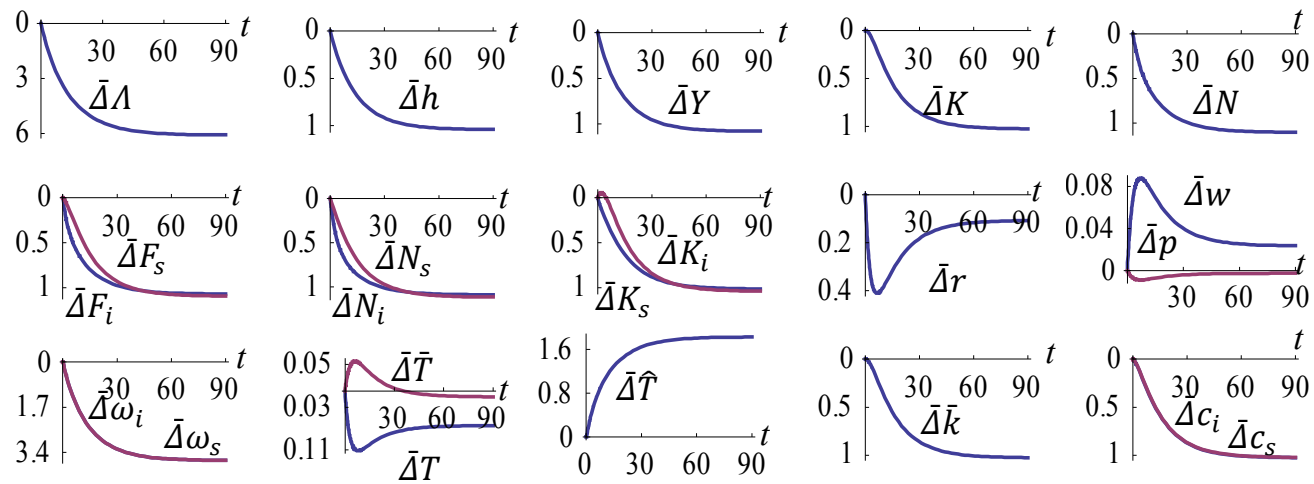

\section{Figure 3. Lower Trust in Society}

\subsection{The propensity to accumulate guanxi rises}

In a society like China where guanxi penetrates almost every aspect of Chinese life, people tend to increasingly emphasize guanxi as their life becomes more complicated. One more friend, one more road, as Chinese proverb says. On the other hand, as society evolves, gunxi goes beyond traditional guanxi based on family and close friends. It extends its scale and scope over time, even though the basic determinants are emotional attachments, reciprocal services, and benefits (Yang and Wang, 2011). We can measure this change by allowing change in the propensity to build human relations. We allow the propensity to accumulate guanxi to be enhanced as follows: $\theta_{0}: 0.02 \Rightarrow 0.022$. We plot the simulation result in Figure 4. The guanxi and human capital are increased. The household spends more hours on accumulating guanxi, works more hours, and has less leisure hours. The national output and national labor fall initially and rise in the long term. The national wealth falls. The consumer goods sector expands. The capital goods sector shrinks initially and expands in the long term. The rate of interest and the price of consumer goods rise. The wage rate falls. The costs of establishing human relations become more expensive. Per household wealth and consumption levels of two goods fall. We see that the people consume less and own less wealth, they spend more time and more resources on guanxi building. 


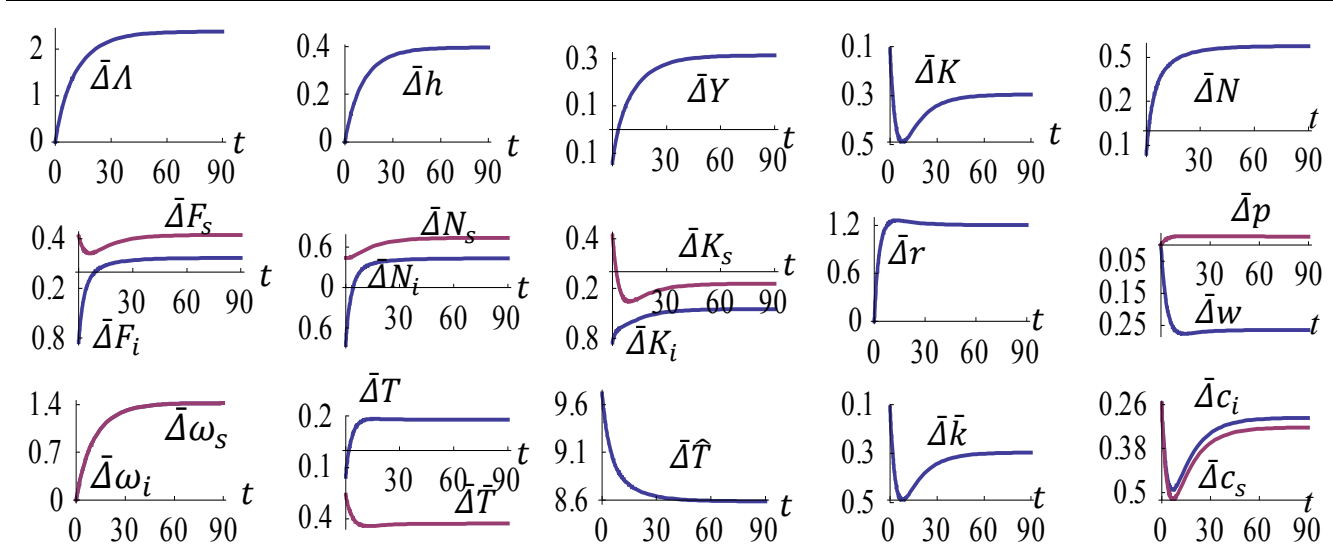

Figure 4. The Propensity to Accumulate Guanxi Rises

\subsection{Negative effects of guanxi being strengthened}

As pointed out by Wang (2007), guanxi is a highly exclusive network within which the members are closely dependent on each other. Only insiders within the guanxi net can use its relational resources, while outsiders can hardly do. Further sophistication of Guanxi nets the society may make the society much less effectively apply its human capital. We deal with the effects of the following change in the human capital function

$$
h(t)=0.8 e^{0.2 \Lambda(t)-0.1 \Lambda^{1.2}(t)} \Rightarrow 0.8 e^{0.2 \Lambda(t)-0.105 \Lambda^{1.2}(t)} .
$$

The specified change implies that the negative effects of guanxi on guanxi building are strengthened. This happens, for instance, due to a change in social environment, some firms may have a higher propensity to employ people who are not very suitable for the jobs but have close guanxi with the firms' bosses. This results in reduction of human capital for the economy partly because some people are discouraged to have high human capital. The simulation result is plotted in Figure 5. The guanxi and the human capital fall. The national output, national labor and national capital are all reduced. The two sectors shrink. The rate of interest and the price of consumer goods are slightly affected. The household spends less time on building guanxi and more hours on work and leisure. Per unit of time costs fall. The consumption levels and wealth are reduced. We see that the national economic growth and people's living conditions suffer from the change. 
Wei-Bin Zhang.

Economic Growth and Human Networking
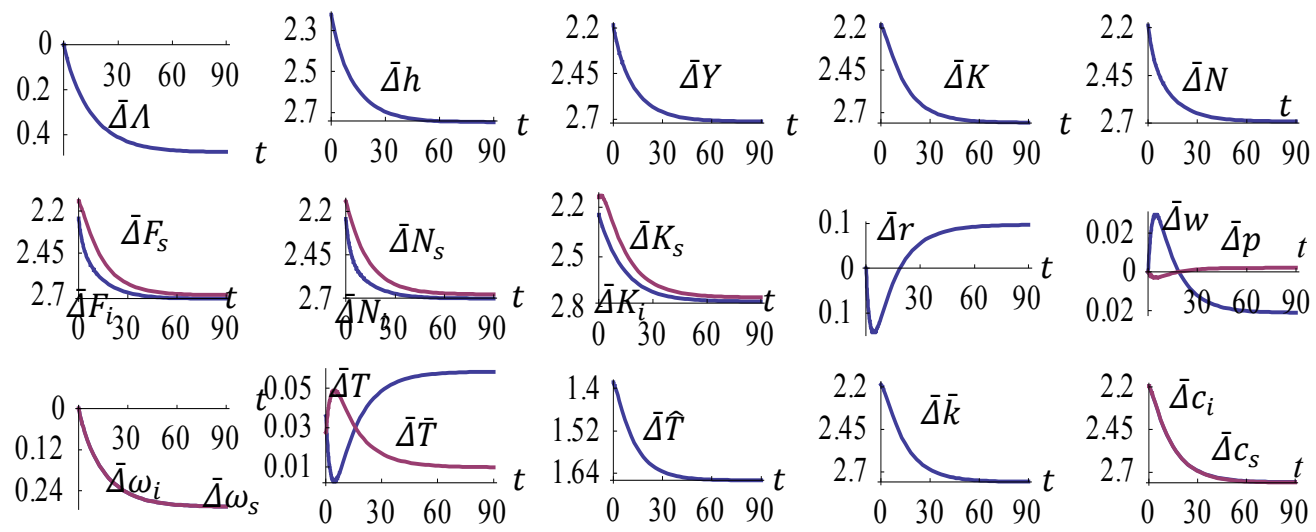

Figure 5. Negative Effects of Guanxi Being Strengthened

\subsection{The total factor productivity of the capital sector rises}

We now study what happen to the economic system when the total factor productivity of the capital sector rises as follows: $A_{i}: 1 \Rightarrow 1.05$. The result is plotted in Figure 6 . The guanxi and human capital are augmented. In the short run the household spends less time on guanxi and leisure and more hours on work; in the long run the household spends more time on guanxi and fewer hours on work and leisure. The national wealth and national output rise. The total labor supply changes slightly. The consumer goods sector shrinks initially and expands in the long term. The capital goods sector expands. The rate of interest rises initially and changes slightly in the long term. The price of consumer goods and wage rate rises. The costs of building guanxi rise. Per household wealth and consumption levels are enhanced in the long term. 

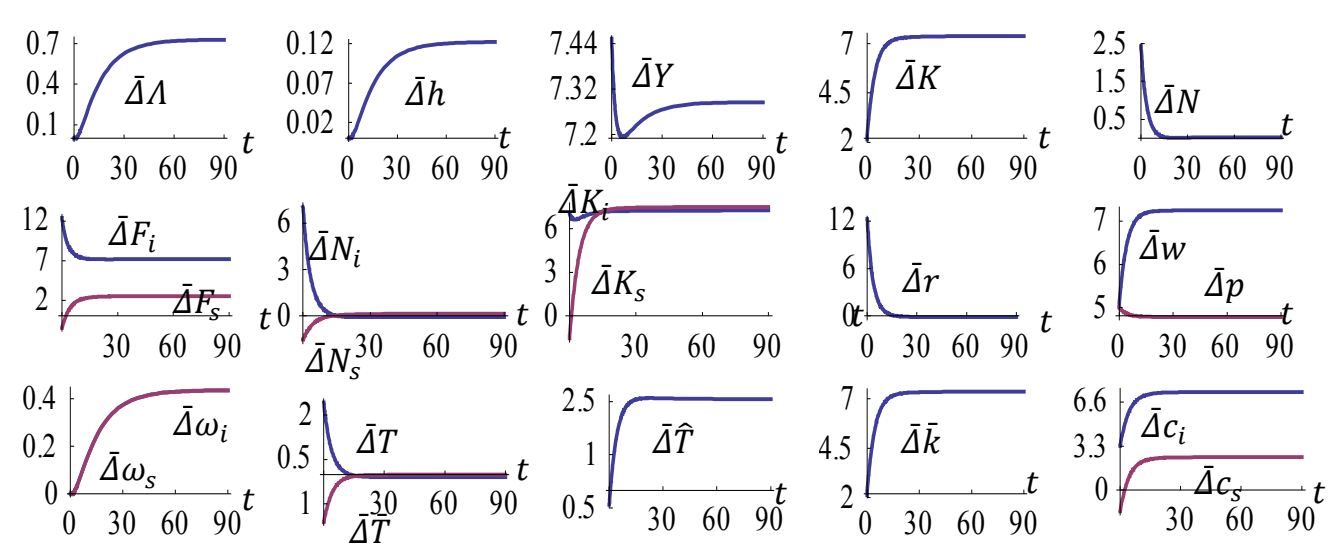

Figure 6. The Total Factor Productivity of the Capital Sector Rises

\subsection{The cost of establishing guanxi rises}

We study the movement of economic system when the cost function of guanxi accumulation in term of capital goods changes as follows

$$
\omega_{i}(\Lambda(t))=0.4 \Lambda^{0.6}(t) \Rightarrow 0.42 \Lambda^{0.6}(t) .
$$

We plot the simulation result in Figure 7. For a given level of guanxi, it costs more for the household to build guanxi in term of capital goods. The guanxi and human capital fall. The household spends fewer hours on guanxi and more hours on leisure and work. The national output, national labor force and national wealth rise initially and fall in the long term. The wage rate and rate of interest rise slightly. The price of consumer goods falls. The capital goods sector expands and the consumer goods sector shrinks. The cost of guanxi in term of capital goods rises and in term of consumer goods falls. The per household wealth and consumption levels of two goods rise initially and fall in the long term. 
Wei-Bin Zhang.

Economic Growth and Human Networking

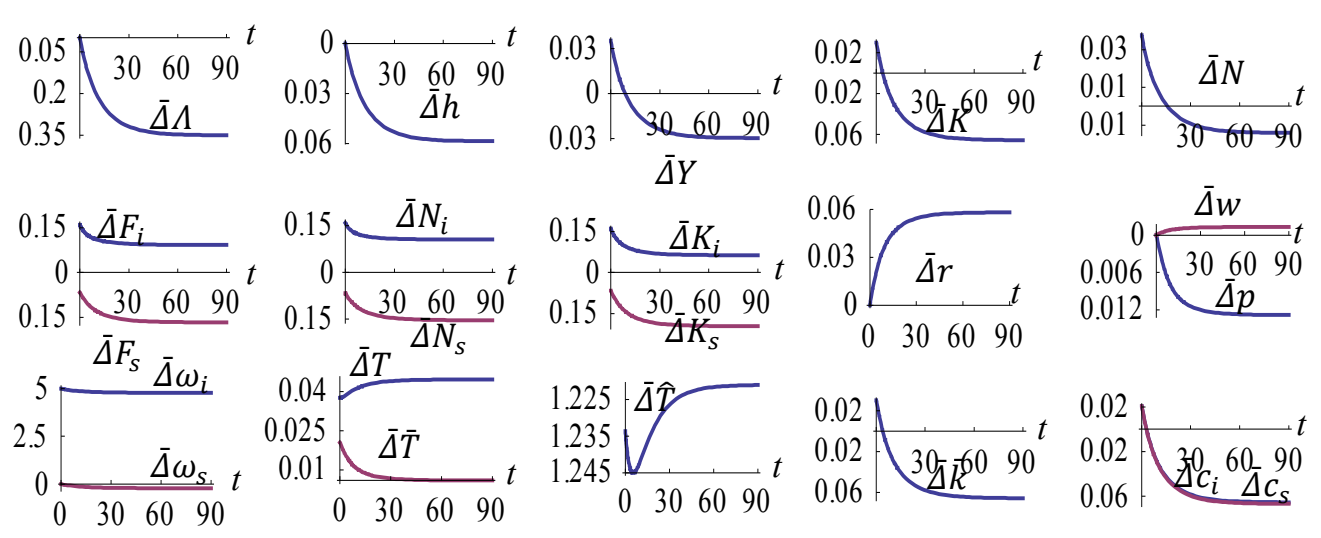

Figure 7. The Cost of Establishing Guanxi Rises

\section{6. $A$ rise in the propensity to accumulate wealth}

We allow the propensity to accumulate wealth to be enhanced as follows: $\lambda_{0}: 0.7 \Rightarrow 0.71$. We plot the simulation result in Figure 8 . The household has more wealth and the economy has more capital. The national output and labor force are augmented. The guanxi and human capital are enhanced. The household spends few hours on guanxi in the short term and more in the long term. The household spends more hours on work and fewer on leisure. The capital consumer goods sector shrinks initially and expands in the long term. The consumer goods sector expands. The wage rate rises. The rate of interest and price of consumer goods are reduced. The costs of building guanxi are enhanced. The consumption levels of two goods are reduced initially and augmented in the long term. 

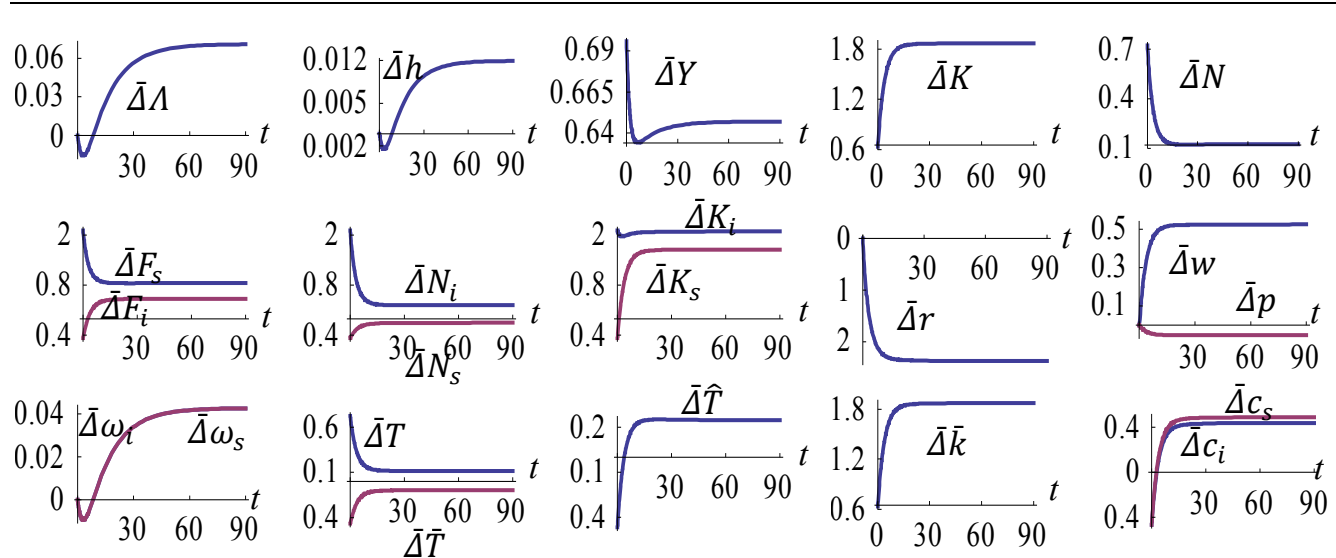

\section{Figure 8. A Rise in the Propensity to Accumulate Wealth}

\subsection{Lower return to scale in building guanxi}

We deal with the effects when guanxi accumulation has lower return to scale as follows: $\chi: 0.4 \Rightarrow 0.45$. The simulation result is provided in Figure 9. The guanxi and human capital fall. The household spends more hours on guanxi. In the long run the household spends few hours on work and leisure. The national capital, national output, and national output fall. The wage rate rises and rate of interest fall. The price of consumer goods is slightly affected. The two sectors shrink. The household has less wealth and consumes less of the two goods.
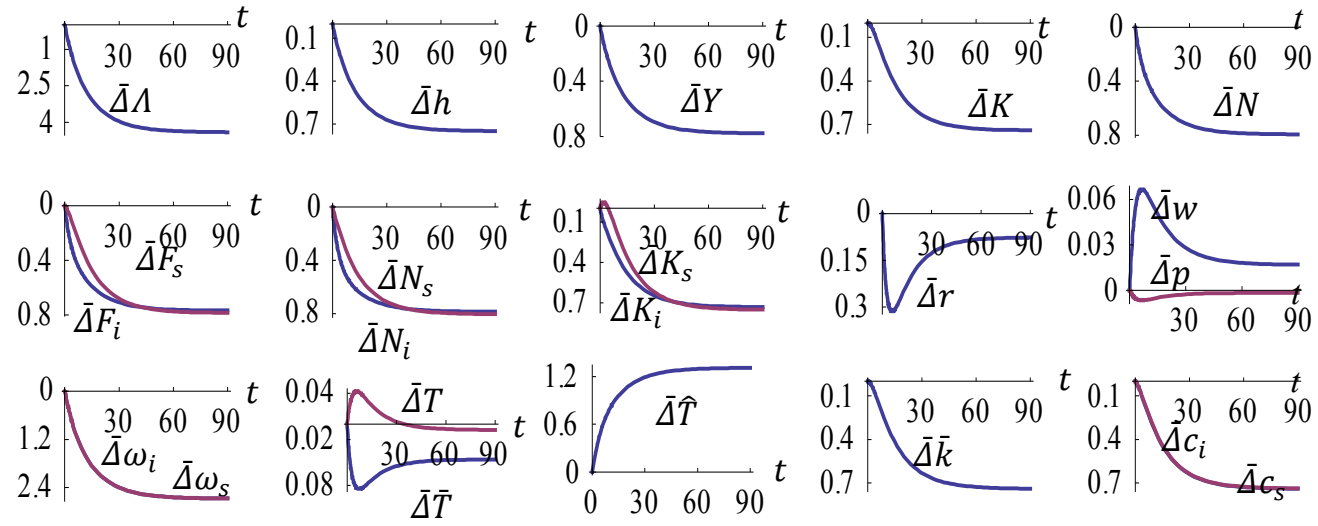

Figure 9. Lower Return to Scale in Building Guanxi 
Wei-Bin Zhang.

Economic Growth and Human Networking

\section{Conclusions}

This paper builds a neoclassical two-sector economic growth model with endogenous, wealth, guanxi and human capital in a competitive economy. The model deals with nonlinear dynamic interactions between wealth accumulation, guanxi building, human capital change, and economic structural change under perfectly competitive conditions. This study assumes that guanxi affects (effective) human capital. To build model costs time, consumer goods and capital goods. We simulate the model. The economic system has a stable unique equilibrium point for the chosen parameter values. We are mainly concerned with the effects of changes in some parameters on the equilibrium and transitional processes of the economic dynamics. We get some insights into interdependence between guanxi and economic growth. For instance, if trust deteriorates among member of society which results in a rise in deterioration rate of guanxi, then the guanxi becomes weakened and the human capital falls; the household spends more hours on accumulating guanxi and fewer hours on work; the national output, national capital and national output fall; the wage rate and rate of interest fall; the per household wealth and consumption levels of two goods fall. The society suffers from lost trust. The model of this study is based on many research papers related to economic growth and to Chinese guanxi. The study can be extended and generalized in different ways. As pointed out by Badi, et al. (2017: 204), "Despite the significance of Guanxi networking as the integrated approach to relationship marketing in the Chinese business environment, there remains, however, a limited understanding of structural and relational characteristics of these stakeholder networks, within which value is jointly created and shared." This study is focused on the dynamics of a highly aggregated variable, guanxi. It is desirable to deal with connections by guanxi among heterogeneous households and sectors. We can do more comparative dynamic analysis. It is possible to further develop our model on the basis of the vast literature on the Solow model and the Uzawa twosector growth model.

\section{Appendix: Proving the Lemma}

We confirm the Lemma. Equations (3) and (5) imply

$z \equiv \frac{r_{\delta}}{w}=\frac{\tilde{\alpha}_{i} N_{i}}{K_{i}}=\frac{\tilde{\alpha}_{s} N_{s}}{K_{s}},(\mathrm{~A} 1)$

in which $\tilde{\alpha}_{j} \equiv \frac{\alpha_{j}}{\beta_{j}}, j=i$, s. Inserting (A1) and (2) in (3), we have 
$r_{\delta}=\frac{\alpha_{i} A_{i} z^{\beta_{i}}}{\tilde{\alpha}_{i}^{\beta_{i}}}, w=\frac{\beta_{i} A_{i} \tilde{\alpha}_{i}^{\alpha_{i}}}{z^{\alpha_{i}}}$. (A2)

From (A1), (4) and (5) we get

$p=\frac{\tilde{\alpha}_{s}^{\beta_{s}} r_{\delta}}{\alpha_{s} A_{s} z^{\beta_{s}}}$.

We have

$\bar{y}=R \bar{k}+h T_{0} w,(\mathrm{~A} 4)$

where $R \equiv 1+r$. Inserting (11) in (14) yields

$\left(\gamma \bar{N}+\frac{\theta \bar{N} p \omega_{s}}{\bar{\omega}}\right) \bar{y}=p F_{s}$. (A5)

Inserting (5) in (A5) yields

$N_{S}=R_{S} \bar{y},(\mathrm{~A} 6)$

where

$R_{s}(z, \Lambda) \equiv\left(\gamma \bar{N}+\frac{\theta \bar{N} p \omega_{s}}{\bar{\omega}}\right) \frac{\beta_{s}}{w}$.

From (8) and (11) we have:

$T=T_{0}-\frac{\sigma \bar{y}}{h w}-\frac{\theta \bar{y}}{\bar{\omega}}$. (A7)

Insert (A6) in (1)

$N=T_{0} h \bar{N}-R_{N} \bar{y},(\mathrm{~A} 8)$

where

$R_{N} \equiv\left(\frac{\sigma \bar{y}}{h w}+\frac{\theta}{\bar{\omega}}\right) h \bar{N}$.

Equations (13), (A8) and (A6) imply

$N_{i}=T_{0} h \bar{N}-\left(R_{N}+R_{S}\right) \bar{y},(\mathrm{~A} 9)$

From (13) and (16) we have

$$
\bar{k} \bar{N}=K_{i}+K_{s} .(\mathrm{A} 10)
$$


Wei-Bin Zhang.

Economic Growth and Human Networking

Inserting (A1) in (A10) yields

$z \bar{k} \bar{N}=\tilde{\alpha}_{i} N_{i}+\tilde{\alpha}_{s} N_{s}$ (A11)

Inserting (A6) and (A9) in (A11) yields

$z \bar{k}=\tilde{\alpha}_{i} h T_{0}-\bar{R} \bar{y},(\mathrm{~A} 12)$

where

$\bar{R} \equiv \frac{\tilde{\alpha}_{i} R_{N}+\tilde{\alpha}_{i} R_{S}-\tilde{\alpha}_{s} R_{S}}{\bar{N}}$.

Inserting (A4) in (A12) yields

$\bar{k}=\Psi(z, \Lambda) \equiv \frac{\tilde{\alpha}_{i} h T_{0}-h T_{0} w \bar{R}}{z+\bar{R} R}$

We thus show that all the variables are expressed as functions of $z$ and $\Lambda$ at any point in time by the following procedure: $r$ and $w$ by (A2) $\rightarrow p$ by (A3) $\rightarrow \bar{k}$ by (A13) $\rightarrow \bar{y}$ by (A4) $\rightarrow K$ by (16) $\rightarrow N_{s}$ by (A6) $\rightarrow T$ by (A7) $\rightarrow N$ by (A8) $\rightarrow N_{i}$ by (A9) $\rightarrow$ $K_{i}$ and $K_{s}$ by (A1) $\rightarrow F_{i}$ by (2) $\rightarrow F_{s}$ by (4) $\rightarrow c_{j s}, c_{i}, \bar{T}$ and $\hat{T}$ by (11). Applying this procedure to (17) and (12) we get

$\dot{\bar{k}}=\Omega_{0}(z, \Lambda) \equiv \lambda \bar{y}-\bar{k},(\mathrm{~A} 14)$

$\dot{\Lambda}=\Omega_{\Lambda}(z, \Lambda) \equiv \frac{u \hat{T}^{a}}{\Lambda^{\chi}}-\delta_{\Lambda} \Lambda$. (A15)

Taking derivatives of (A13) in time yields

$\dot{\bar{k}}=\frac{\partial \bar{k}}{\partial z} \dot{z}+\frac{\partial \bar{k}}{\partial \Lambda} \dot{\Lambda}$. (A16)

Inserting (A15) and (A14) in (A16) yields

$\dot{z}=\Omega_{z}(z, \Lambda) \equiv\left(\Omega_{0}-\frac{\partial \bar{k}}{\partial \Lambda} \Omega_{\Lambda}\right)\left(\frac{\partial \bar{k}}{\partial z}\right)^{-1}$.

We confirmed the lemma.

\section{References}

1. Ai, J. (2006) Guanxi Networks in China: Its Importance and Future Trends. China \& World Economy 14(5), 105-18. 
2. Alston, J. (1989) Wa, Guanxi, and Inwa: Managerial Principles in Japan, China, and Korea. Business Horizon, March, 26-31.

3. Ambramson, N.R. and Ai, J.X. (1999) Canadian Companies Doing Business in China: Key Success Factors. Management International Review 39, 17-27.

4. Badi, S., Wang, L.S., and Pryke, S. (2017) Relationship Marketing in Guanxi Networks: A Social Network Analysis Study of Chinese Construction Small and Medium-Sized Enterprises. Industrial Marketing Management 60, 204-16.

5. Beugelsdijk, S. and van Schaik, A. (2005) Social Capital and Growth in European Regions: An Empirical Test. European Journal of Political Economy 21, 301-24.

6. Bofota, Y.B., Boucekkine, R.B., and Bala, A.P. (2016) Social Capital as an Engine of Growth: Multisectoral Modelling and Implications. Macroeconomic Dynamics 20, 2093-122.

7. Burmeister, E. and Dobell, A.R. (1970) Mathematical Theories of Economic Growth. London: Collier Macmillan Publishers.

8. Butterfield, F. (1983) China: Alive in Bitter Sea. New York: Coronet Books.

9. Chou, Y.K. (2006) Three Simple Models of Social Capital and Economic Growth. Journal of Socio-Economics 35, 889-912.

10. Fan, Y. (2002) Questioning Guanxi: Definition, Classification and Implications. International Business Review 11, 543-61.

11. Hwang, K.K. (1987) Face and Favor, the Chinese Power Game. The American Journal of Sociology 92 (4), 944-74.

12. Iyer, S., Kitson, M., and Toh, B. (2005) Social Capital, Economic Growth and Regional Development. Regional Studies 39(8), 1015-40.

13. Knack, S. and Keefer, P. (1997) Does Social Capital Have an Economic Payoff? A Cross-Country Investigation. Quarterly Journal of Economics 112, 1251-88.

14. Lee, E. Y.C. and Anderson, A.R. (2007) The Role of Guanxi in Chinese Entrepreneurship. Journal of Asia Entrepreneurship and Sustainability 3(3), 1-16.

15. Leung, T.K.P., Lai, K.H, Chan, R.Y.K., and Wonf, Y.H. (2005) The Roles of Xinyong and Guanxi in Chinese Relationship Marketing. European Journal Marketing 39(5/6), 528-59.

16. Luo, Y.D. (1997) Guanxi: Principles, Philosophies, and Implications. Human Systems Management 16(1), 43-51.

17. Luo, Y.D. (1997) The Changing Chinese Culture and Business Behavior: The Perspective of Intertwinement between Guanxi and Corruption. International Business Review 17(2), 188-93. 
Wei-Bin Zhang.

Economic Growth and Human Networking

18. Putnam, R.D., Leonardi, R., and Nanetti, R. (1993) Making Democracy Work: Civil Traditions in Modern Italy. Princeton, NJ: Princeton University Press.

19. Solow, R. (1956) A Contribution to the Theory of Growth. Quarterly Journal of Economics 70, 65-94.

20. Solow, R.M. (1995) But Verify. The New Republic, Sept. 11, 36-39.

21. Styles, C. and Ambler, T. (2003) The Coexistence of Transaction and Relational Marketing: Insights from Chinese Business Context. Industrial Marketing Management 32(8), 633-42.

22. Su, C.T., Michell, R.K., and Sirgy, M. (2007) Enabling Guanxi Management in China: A Hierarchical Stakeholder Model of Effective Guanxi. Journal of Business Ethics 71(3), 301-309.

23. Swan, T.W. (1956) Economic Growth and Capital Accumulation. Economic Record 32, 334-61.

24. Uzawa, H. (1961) On a Two-Sector Model of Economic Growth. Review of Economic Studies 29, 47-70.

25. Wang, C.L. (2007) Guangxi vs. Relationship Marketing: Exploring Underlying Differences. Industrial Marketing Management 36, 81-6.

26. Watt, L. (1999) Managing in the PRC. Better Management 35(12), 24-8.

27. Wong, M.L. and Huang, P.C. (2015) Culturally Embedded Mechanism, Guanxi in Marketing. Open Journal of Social Sciences 3, 154-58.

28. Wong, Y.D. and Chan, R.Y. (1999) Relationship Marketing in China: Guanxi, Favourism and Adaptation. Journal of Business Ethics 22(2), 107-18.

29. Wong, Y.H. (2008) An Integrated Relationship (Guanxi) Marketing Model in China. Journal of Professional Services Marketing 18(1), 25-48.

30. Yang, Z. and Wang, C.L. (2011) Guanxi as a Governance Mechanism in Business Markets: Its Characteristics, Relevant Theories, and Future Research Directions. Industrial Marketing Management 40(4), 492-95.

31. Yau, O.H., Lee, L.S.Y., Chow, R.P.M., Sin, L.Y.M., and Tse, A.C.B. (2000) Relationship Marketing: The Chinese Way. Business Horizons 53(1), 16-24.

32. Yeung, I.Y.M. and Tung, R.L. (1996) Achieving Business Success in Confucian Societies: The Importance of guanxi. Organisational Dynamics 25(2), 5465 .

33. Zhang, W.B. (1993) Woman's Labor Participation and Economic Growth Creativity, Knowledge Utilization and Family Preference. Economics Letters 42, 105110.

34. Zhang, W.B. (2005) Economic Growth Theory. London: Ashgate. 